\title{
Virulence and Molecular Genotyping Studies of Sporisorium reilianum Isolates in Sorghum
}

Louis K. Prom, USDA-ARS, Southern Plains Agricultural Research Center, College Station, TX 77845; Ramasamy Perumal, Agricultural Research Center, Kansas State University, Hays; Saradha R. Erattaimuthu, Department of Plant Pathology, Kansas State University, Manhattan; John E. Erpelding, USDA-ARS, Crop Genetics Research Unit, Stoneville, MS 38776-0345; Noe Montes, INIFAP, Rio Bravo Experimental Station, Apartado Postal 172, 88900 Rio Bravo, Tamaulipas, Mexico; Gary N. Odvody, Department of Plant Pathology and Microbiology, Texas AgriLife Sciences, Corpus Christi 78406-1412; Charles Greenwald, Department of Plant Pathology and Microbiology, Texas A\&M University, College Station 77843-2182; Zheyu Jin, Baicheng City Academy of Agricultural Science, Jilin Province, P. R. of China, 137000; Richard Frederiksen, Professor Emeritus, and Clint W. Magill, Department of Plant Pathology and Microbiology, Texas A\&M University, College Station 77843-2182

\begin{abstract}
Prom, L. K., Perumal, R., Erattaimuthu, S. R., Erpelding, J. E., Montes, N., Odvody, G. N., Greenwald, C., Jin, Z., Frederiksen, R., and Magill, C. W. 2011. Virulence and molecular genotyping studies of Sporisorium reilianum isolates in sorghum. Plant Dis. 95:523-529.

Head smut, caused by the fungal pathogen Sporisorium reilianum, has been reported with increasing frequency in the grain sorghum growing areas of Texas. To facilitate analysis of changes in pathogen virulence, four inoculation techniques were examined: soil and teliospore mixture, seed coating, media placement, and syringe injection. Of the four, syringe injection was determined to be the most effective. Inoculations of sorghum host differentials BTx643, BTx7078, BTx635, SC170-6-17 (TAM2571), SA281 (Early Hegari), and Tx414 showed 23 of 32 Texas isolates were race 4 . Two isolates from College Station, TX, were classified as race 1 , but no race 2 or 3 isolates were found. New, virulent races 5 and 6 were identified among isolates from south Texas.

combinations, genetic diversity was assessed in DNA samples from 49 $S$. reilianum isolates, including 44 sorghum isolates from Texas, two from Uganda, and one from Mali; and two maize isolates from Mexico. Single-base extensions with EcoRI and MseI primers in the selective amplification increased the number of informative polymorphic bands. High genetic dissimilarity $(50 \%)$ was observed between isolates originating from maize and those originating from sorghum. The resultant dendrogram, made using cluster analysis, grouped the Texas $S$. reilianum isolates into four small clusters with $\geq 82 \%$ similarity. Other than for two race 6 isolates from Weslaco, TX, no evidence for geographical or other restrictions on gene flow was evident.
\end{abstract} Using 16 amplified fragment length polymorphism (AFLP) primer
Sorghum (Sorghum bicolor (L.) Moench) is the world's fifth most important cereal crop, providing food, feed, fiber, and biofuel across a range of environments and production systems. Its remarkable ability to thrive under adverse conditions, especially drought, makes this crop an important "failsafe" in the global agroecosystem (13). However, production can be limited by a number of biotic stresses. Head smut, caused by the soilborne facultative biotrophic basidiomycete Sporisorium reilianum (Kühn) Langdon \& Fullerton (syns. Sphacelotheca reiliana (Kühn) G.P. Clinton and Sorosporium reilianum (Kühn) McAlpine), is an important sorghum disease. Head smut has been reported from all parts of the world where sorghum is grown. Once present in a cropping area, the pathogen is very difficult to remove from the soil, even by adopting crop rotation to prevent annual soil reinoculation. S. reilianum infects at the seedling stage, but symptoms are not expressed until flowering. Disease results in the inability of infected plants to produce grain. S. reilianum is one of the few smuts not controllable by seed treatment, leaving host resistance as the only practical control technique (7). Disease incidence has recently increased dramatically in sorghum fields in the Coastal Bend area of Texas (G. N. Odvody, personal observation).

The use of genetic resistance to head smut in sorghum has been hampered by the lack of efficient and effective inoculation methods

Corresponding author: C. Magill, E-mail: c-magill@tamu.edu

L. K. Prom and R. Perumal have equal authorship in this article.

Accepted for publication 28 January 2011.

doi:10.1094/PDIS-10-10-0720

(C) 2011 The American Phytopathological Society for identification of resistant genotypes. Field screening under natural infection at hot spots with high infection frequencies requires repeated trials for reliable results because of fluctuating soil temperature unfavorable for disease development. Soil temperatures below $21^{\circ} \mathrm{C}$ and above $31^{\circ} \mathrm{C}$ seriously reduce the percentage of infection (21). Also, erratic distribution of inoculum in the soil leads to high rates of disease escape, even in fully susceptible cultivars. An inoculation method developed by Edmunds (5) using a hypodermic syringe also resulted in inconsistent disease expression in our hands. Craig and Frederiksen (3) developed a soil-based inoculation protocol for inducing symptoms of infection by $S$. reilianum in sorghum seedlings and compared the relationship of these symptoms to known head smut responses using a small sample of the sorghum germplasm collection. It is not clear if all susceptible genotypes would be detected by this technique. Hence, Edmunds' (5) hypodermic syringe method, with some modifications by Ramasamy et al. (21), was assessed in this study as a way to achieve accurate and reliable disease scoring.

Three potentially different host mechanisms resulting in head smut resistance have been described $(3,8)$. The three were defined as: R1, horizontal, resistance to natural infection but susceptibility to all races following syringe inoculation; R2, vertical, specific resistance to some races of $S$. reilianum and susceptibility to others, with the same response to natural infection as to syringe inoculation; and R3, horizontal resistance to natural infection and syringe inoculation. Resistant cultivars have been developed to control the disease, but because of the pathogen's ability to produce new races that are virulent to previously resistant sorghum cultivars, head smut remains a sporadically important disease. In the United States, four pathogenic races (1 to 4) were defined previously among sorghum isolates of $S$. reilianum on the basis of reactions to a series of host differentials (8). Races 1 and 3 were also found on cultivars/hybrids grown in Queensland, Australia, by 
Dodman et al. (4). Since the observations by Frederiksen and Reyes (8) 30 years ago, no experimental classification of head smut races on sorghum has been reported in the United States. The recent increase of $S$. reilianum in the grain sorghum areas of the United States may be due to the introduction of susceptible sorghum hybrids, the appearance of more virulent races, or both.

Even though head smut is widely distributed where sorghum is grown in Texas, reliable information is lacking on existing pathotypes and their distribution within the state. A molecular description of the genetic differences between isolates could provide insights on the extent of genetic diversity of $S$. reilianum and a basis for further investigation of the mechanisms that generate that variation. DNA-based markers can provide useful insights into population structure and offer the possibility of direct identification of different races $(19,23)$.

The genetic structure of 459 isolates of $S$. reilianum from field populations in Mexico, Niger, and the United States was previously characterized in a limited fashion (18) using restriction fragment length polymorphism (RFLP) and random amplified polymorphic DNA (RAPD) techniques. Advances in technology since that time offer opportunities to more effectively sample genomic differences. For example, the use of amplified fragment length polymorphisms (AFLP) has practical applications for DNA fingerprinting of prokaryotes and eukaryotes. This technique provides a high degree of flexibility because different restriction enzymes can be used and because the nature and number of selective nucleotides added can be manipulated to limit amplification to a subset of the fragments generated and thus to account for differences in genome size $(9,14,26)$. AFLP fingerprinting has wide taxonomic applicability, as demonstrated by its effective use in a variety of taxa including bacteria (9) and fungi (15). Few prior AFLP studies have been conducted in basidiomycetous plant pathogenic fungi. Examples include work by Bakkeren et al. (1) in several fungal species, including isolates from the order Ustilaginales, and by Zhou et al. (27) with the rice false smut fungus, Ustilaginoidea virens.

Consequently, this research was conducted with three objectives: (i) identify an efficient and reliable method of inoculation for resistance screening; (ii) establish the pathotypes of head smut isolates collected from different locations in Texas; and (iii) examine the population structure and genetic diversity of $S$. reilianum isolates using AFLP genotyping analysis.

\section{Materials and Methods}

Head smut isolates. For pathotype analysis, a total of 32 sorghum head smut (S. reilianum) isolates collected in 2004 from four

Table 1. Origin of sorghum and maize Sporisorium reilianum isolates used in study of inoculation methods

\begin{tabular}{|c|c|}
\hline imber $(01-57)$ and identifier & Location - date of collection \\
\hline \multicolumn{2}{|c|}{ Sorghum isolates used for pathotype analysis } \\
\hline $01 \mathrm{HSC}$ to $07 \mathrm{HSC}$ & Corpus Chris \\
\hline & \\
\hline & Beer \\
\hline 27 HSCS to $32 \mathrm{HSC}$ & College Station, $]$ \\
\hline \multicolumn{2}{|c|}{$\begin{array}{l}\text { Additional sorghum and maize isolates included in AFLP } \\
\text { genotyping analysis }^{\mathrm{z}}\end{array}$} \\
\hline & College Station, TX - July 200 \\
\hline & \\
\hline & , TX - July 2 \\
\hline $37 \mathrm{HSU}$ and $38 \mathrm{HSU}$ & $\begin{array}{l}\text { Uganda, prior to } 2000 \text {, exact } \\
\text { date unknown }\end{array}$ \\
\hline 39 HSM & $\begin{array}{l}\text { Mali, prior to 2000, exact date } \\
\text { unknown }\end{array}$ \\
\hline $40 \mathrm{Hs}$ & n, TX - July 2005 \\
\hline $\begin{array}{l}46 \mathrm{HSZm} \text { and } 47 \mathrm{HSZm} \text { (maize } \\
\text { isolates) }\end{array}$ & $\begin{array}{l}\text { Mexico, prior to } 2000 \text {, exact } \\
\text { date unknown }\end{array}$ \\
\hline $48 \mathrm{HSTt}$ and $49 \mathrm{HSTt}$ & Taft, T \\
\hline & Wharton, TX - July 2005 \\
\hline $53 \mathrm{HSC}, 55 \mathrm{HSC}$, and HSC 57 & Corpus Christi, TX - July 2006 \\
\hline
\end{tabular}

${ }^{\mathrm{z}}$ Isolates $07 \mathrm{HSC}, 13 \mathrm{HSW}, 15 \mathrm{HSW}$, and $26 \mathrm{HSB}$ were not included in amplified fragment length polymorphism (AFLP) genotyping studies. locations in Texas (Corpus Christi, Weslaco, Beeville, and College Station) were used. For AFLP genotyping, the study included 16 additional isolates collected in different years from different locations in Texas (Corpus Christi, College Station, Brandon, Taft, Wharton, Victoria, and Taylor) along with three African isolates (Uganda and Mali) and two maize isolates of $S$. reilianum collected from Mexico (Table 1). The isolates 07, 13, 15, and 26 used in virulence studies were not included in AFLP genotyping studies due to poor amplification.

Inoculation methods. Four sorghum differentials were used for the study: BTx643, BTx7078, and SC170-6-17, all susceptible; and BTx635, resistant. Four inoculation methods were employed, as described below. Thirty-two isolates, listed in Table 1, were evaluated on four inbred sorghum differentials grown under greenhouse conditions to ensure environmental uniformity. Each inoculation method was applied to each of the four differentials using each isolate, and experiments were conducted using a randomized complete block design. There were three simultaneous replicates, with five plants in each replicate. All four inoculation methods were tested simultaneously, using eight isolates at a time, between March and October 2005, and the experiment was repeated during the same period in 2006.

The soil and teliospore mixture method was carried out as described by Osorio and Frederiksen (20). Soil mix (Metro mix 700; Scotts-Sierra Horticultural Products Company, Maryland, $\mathrm{OH}$ ) and teliospores were mixed thoroughly at a rate of 50:1 ( vol/vol) and dispensed into 5-gal. pots (Hummert International, Earth City, MO). Seeds were planted in the teliospore-enriched soil.

The seed coating technique was performed according to Marley (16). One gram of seeds and $0.5 \mathrm{~g}$ of teliospores were mixed in a container with latex sticker (Rhoplex 15BJ; Rohm and Haas, Philadelphia, PA). After thorough mixing using a sterilized scalpel, seeds were allowed to dry under a laminar flow hood for 3 to 4 min before planting.

For media placement, dry teliospores from each isolate were first washed in $70 \%$ ethanol for $5 \mathrm{~min}$, allowed to dry under a laminar flow hood, rinsed twice in sterilized water, and then plated separately on half-strength potato dextrose agar ( $1 / 2$ PDA). The culture plates were incubated in the dark at $28^{\circ} \mathrm{C}$ for 72 to $96 \mathrm{~h}$. Before use, the sporidial colonies were verified under a dissecting microscope for lack of contamination by other fungi. For each pot, media with sporidial colonies from two plates of each isolate were used. Seeds were sandwiched between two 1/2 PDA media blocks containing sporidial colonies, placed in pots containing soil, and then covered with a thin layer of soil before watering.

The syringe injection technique was similar to the one described by Edmunds (5) as modified by Ramasamy et al. (21) to include growth of sporidial colonies from each of the 32 head smut isolates on potato dextrose broth (PDB). After 4 days growth on a rotary shaker set at $150 \mathrm{rpm}$, the resulting sporidial inoculum (milky color) was filtered through cheesecloth and adjusted to a concentration of $1 \times 10^{5}$ spores $\mathrm{ml}^{-1}$. The resulting sporidial suspensions were used to inoculate five plants in each replicate. Plants were inoculated by injection below the apical meristem of 18- to 20-day-old seedlings (approximately $10 \mathrm{~cm}$ in height) between 4:00 and 7:00 P.M. to avoid heat-related drying. Fresh inoculum was prepared separately for each experiment, and each plant was injected with 0.5 to $1.0 \mathrm{ml}$ of sporidial suspension using a Precision Glide Needle \# $22 \mathrm{G} \times 1$ in. (Becton, Dickinson and Co., Franklin Lakes, NJ) attached to a 30-ml hypodermic syringe.

Data analysis. Data for head smut incidence for each replicate across the four sorghum differentials and $32 \mathrm{~S}$. reilianum isolates were analyzed using PROC GLIMMIX (SAS, version 9.1, SAS Institute, Cary, NC) to determine disease incidence for each of the inoculation techniques. Comparisons among techniques were conducted using $\mathrm{T}$ grouping of the least-squares means at the $5 \%$ probability level.

Identification of races. Results from the syringe injection method conducted during 2005 and 2006 with the four sorghum differentials and the $32 \mathrm{~S}$. reilianum isolates were used for identifi- 
cation of head smut races. The experiment was repeated with the same 32 isolates in February 2009 and including two additional differentials, SA281 (Early Hegari) and Tx414, which had been used previously by Frederiksen and Reyes (8) to establish $S$. reilianum races in sorghum. The qualitative scoring system (susceptible or resistant) was used to assign the phenotypes without intermediate reaction types. At flowering, as shown in Figure 1, the panicle is replaced by sori. Sori have a variety of appearances that can be seen in the main head and/or tillers. Resistant plants have regular flowering with normal grain development and no sori. To avoid disease escapes and obtain accurate disease scores, plants with a healthy inflorescence at the time of initial flowering were cut and the side tillers that developed were also examined for signs of systemic infection at flowering.

Molecular diversity. Head smut-infected sorghum plants were sampled by bagging individual sori, which were allowed to dry at room temperature for a week before the teliospores were passed through a fine metal sieve to separate them from plant debris. The harvested teliospores were placed in sterile plastic culture tubes and stored at $4{ }^{\circ} \mathrm{C}$. To avoid bacterial contamination during culture, dry teliospores of each isolate were washed in $70 \%$ ethanol for 5 min, suspended in sterile water, plated on PDA, and incubated in the dark at $28^{\circ} \mathrm{C}$ for 72 to $96 \mathrm{~h}$. Isolated single-sporidium colonies were then transferred to 250 -ml flasks containing $100 \mathrm{ml}$ PDB for increase on a rotary shaker at $150 \mathrm{rpm}$ for 4 days. Sporidial cultures multiplied from each selected single-spore colony were collected with suction onto Whatman no. 1 filter paper, transferred to aluminum foil, and frozen immediately by immersion in liquid nitrogen. The dried sample was powdered in liquid nitrogen using a mortar and pestle. DNA was extracted using a MasterPure Yeast DNA Purification kit (EPICENTRE Biotechnologies, Madison, WI), and the DNA was diluted to a working concentration of 50 $\mathrm{ng} / \mu \mathrm{l}$ by adding $1 \times \mathrm{TE}(10 \mathrm{mM}$ Tris- $\mathrm{HCl}[\mathrm{pH} 8.0], 1 \mathrm{mM}$ EDTA).

For the 49 single-spored isolates collected from sori, AFLP template preparation and polymerase chain reaction (PCR) conditions were as described previously $(12,26)$ with the following modifications. Two restriction endonucleases, EcoRI (2.5 U) and MseI (5U), were used to digest $100 \mathrm{ng}$ of genomic DNA in a $20-\mu \mathrm{l} \mathrm{reac}-$ tion also containing $2 \mu \mathrm{l}$ of $10 \times$ restriction-ligation buffer. The reactions were incubated for $2 \mathrm{~h}$ at $37^{\circ} \mathrm{C}$. The ligation reaction volume of $5 \mu \mathrm{l}$ was prepared to contain $0.5 \mathrm{U}$ of T4 DNA ligase (New England Biolabs, Beverly, MA), $2.5 \mathrm{pmol}$ of EcoRI and 25 pmol of MseI adapters, $0.5 \mathrm{mM}$ ATP, and $0.5 \mu \mathrm{l}$ of $10 \times$ restrictionligation buffer. After combining $5 \mu$ of ligation mix with the restricted genomic DNA fragments, ligation was allowed to proceed overnight at $37^{\circ} \mathrm{C}$. The adapter-ligated DNA $(25 \mu \mathrm{l})$ was diluted 1:10 with TE buffer $(225 \mu \mathrm{l})$ to serve as template in the preselective PCR and stored at $-20^{\circ} \mathrm{C}$. Preamplification of the dilute template DNA was performed with AFLP primers having no EcoRI $(+0)$ and one MseI (+1) selective nucleotide. Twenty-microliter PCR reactions were performed containing $5 \mu \mathrm{l}$ of dilute template DNA, 30 ng each of EcoRI +0 and $M s e \mathrm{I}+1$ primers, $0.4 \mathrm{U}$ of GoTaq DNA
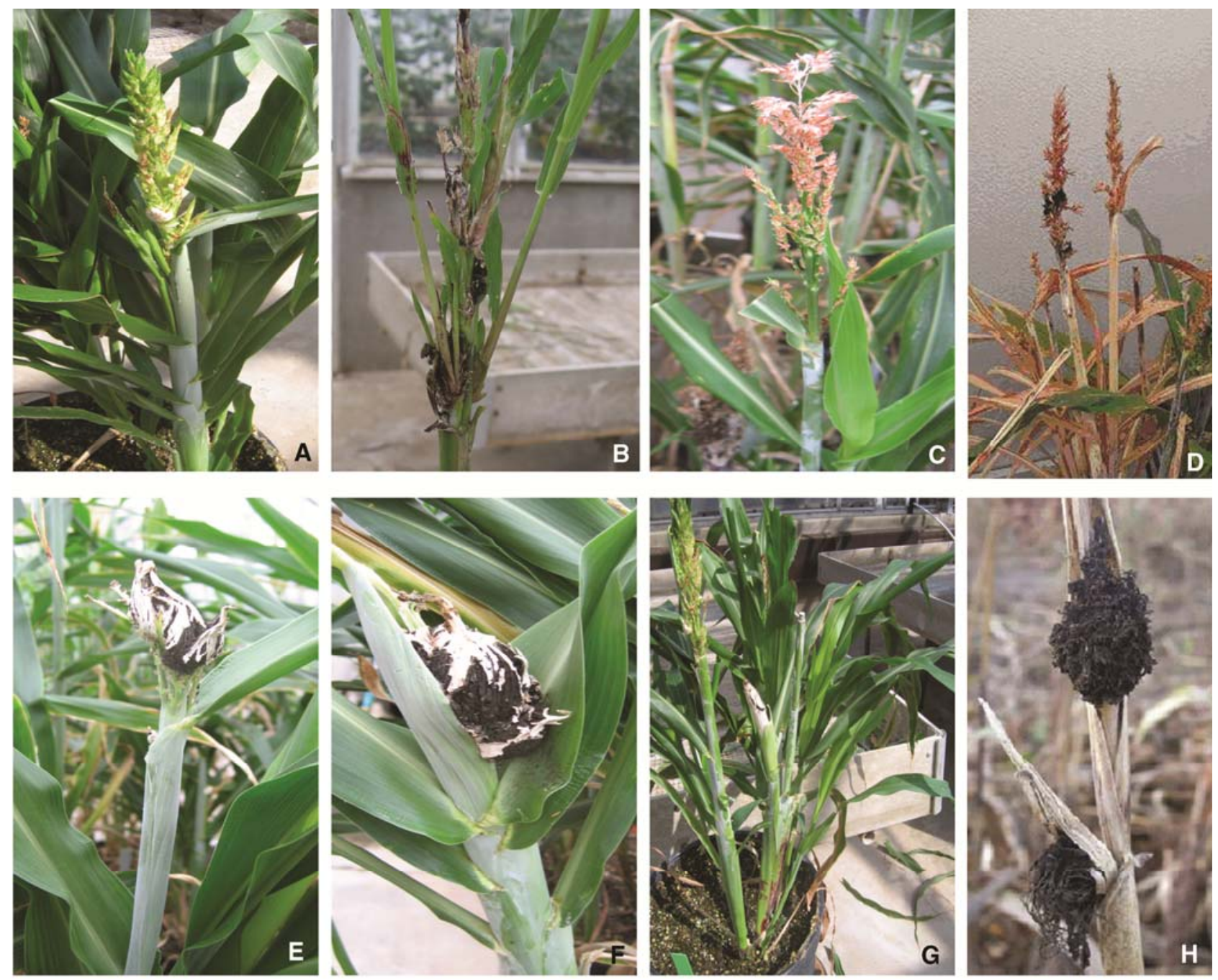

Fig. 1. Characteristic symptoms of sorghum head smut: A, phylloidial miniature leaves with smut gall; B, smutted panicles with characteristic witches'-broom symptom; C, bleached sterile panicle; D, bleached sterile panicle with smut gall; $\mathbf{E}$, sorus covered by a thick white membrane (peridium); $\mathbf{F}$, stunted growth due to a lack of elongation of the peduncle and rupturing of the peridium; $\mathbf{G}$, late infection of head smut in the secondary tillers replaced by smut sori; $\mathbf{H}$, primary and secondary tillers completely replaced with black sori. 
Polymerase (Promega), $4 \mu \mathrm{l}$ of $5 \times$ GoTaq DNA Polymerase buffer, $1.6 \mu \mathrm{l}$ of $2.5 \mathrm{mM}$ dNTPs, and $2 \mu \mathrm{l}$ of $25 \mathrm{mM} \mathrm{MgCl}_{2}$. Preamplification reactions were performed for 20 cycles of: $30 \mathrm{~s}$ at $94^{\circ} \mathrm{C}, 1 \mathrm{~min}$ at $56^{\circ} \mathrm{C}$, and $1 \mathrm{~min}$ at $72^{\circ} \mathrm{C}$. Following preamplification, the reactions were diluted 10 -fold with $0.5 \times$ TE buffer and used as template for selective amplification. Selective amplification reactions were performed using EcoRI primers with one selective nucleotide $(E c o \mathrm{RI}+\mathrm{A}, E c o \mathrm{RI}+\mathrm{T}, E c o \mathrm{RI}+\mathrm{G}$, or $E c o \mathrm{RI}+\mathrm{C})$ and all four possible MseI primers (MseI + A, MseI + T, MseI + G, and MseI + C), resulting in a total of $16+1 /+1$ unique primer combinations. The description of the adapters and preamplification and selectiveamplification primer sequences used in this study are detailed in Table 2. IRD (Infra-red Dye)-labeled EcoRI primers, obtained from MWG (High Point, NC), were diluted to $1 \mu \mathrm{M}$ according to the manufacturer's recommendation and stored at $-20^{\circ} \mathrm{C}$ in the dark until ready for use. Selective AFLP reactions were performed in a final volume of $10 \mu \mathrm{l}$ containing $2 \mu \mathrm{l}$ of dilute preamplified template DNA (50 pg), $15 \mathrm{ng}$ MseI selective primer, $0.3 \mu \mathrm{l}$ IRD-labeled EcoRI selective primer, $0.8 \mu \mathrm{l}$ of $2.5 \mathrm{mM}$ dNTPs, and $1 \mu \mathrm{l}$ of 25 $\mathrm{mM} \mathrm{MgCl}$. Selective amplification reactions were performed as follows: 1 cycle of $2 \mathrm{~min}$ at $94^{\circ} \mathrm{C}$, followed by 36 cycles of $30 \mathrm{~s}$ at $94^{\circ} \mathrm{C}, 30 \mathrm{~s}$ annealing step (see below), and $1 \mathrm{~min}$ at $72^{\circ} \mathrm{C}$. The annealing temperature in the first cycle was $65^{\circ} \mathrm{C}$ and was subsequently reduced $0.7^{\circ} \mathrm{C}$ for each of the next 12 cycles and was then continued at $56^{\circ} \mathrm{C}$ for the remaining 23 cycles. Reactions were complete after a final extension of $5 \mathrm{~min}$ at $72^{\circ} \mathrm{C}$.

The AFLP amplification products were analyzed using a LICOR-NEN Model 4300 dual-dye automated DNA Analyzer. Following amplification, an equal volume $(5 \mu \mathrm{l})$ of PCR products labeled using the IRD-700 nm EcoRI primer (EcoRI + A and EcoRI $+\mathrm{G})$ were pooled with the products labeled with the IRD-800 nm EcoRI primer $(E c o R I+C$ and $E c o R I+T)$. Basic fusion dye $(2 \mu \mathrm{l})$ (LI-COR) was added to each pooled sample, and the samples were denatured for $5 \mathrm{~min}$ at $95^{\circ} \mathrm{C}$. Each sample $(1 \mu \mathrm{l})$ was loaded on a $6.5 \%$ polyacrylamide gel containing $7 \mathrm{M}$ urea. Gels were cast using LI-COR 25-cm plates with 0.25-mm-thick spacers and comb. Electrophoresis was performed at a constant power of $40 \mathrm{~W}$ and a constant temperature of $47.5^{\circ} \mathrm{C}$ for $3 \mathrm{~h}$. Markers were scored manually for presence (1) or absence (0) of each band in the AFLP analysis. Bands of different electrophoretic mobility were assumed to be nonallelic, while bands of the same mobility were assumed to be alleles. A pair-wise similarity matrix was calculated using the Jaccard coefficient (10):

$$
\mathrm{MS}_{i j}=\mathrm{N}_{i j} /\left(\mathrm{N}_{i i}+\mathrm{N}_{i j}+\mathrm{N}_{j j}\right)
$$

where $\mathrm{MS}_{i j}$ is the DNA marker similarity index between the $i$ th and $j$ th genotype, $\mathrm{N}_{i j}$ is the number of bands present in both genotypes, $\mathrm{N}_{i i}$ is the number of bands present in the $i$ th genotype, but lacking

Table 2. Description of the primers used for amplified fragment length polymorphism analysis

\begin{tabular}{ll}
\hline Primers and their function & Sequence $\left(\mathbf{5}^{\prime} \mathbf{-} \mathbf{3}^{\prime}\right)$ \\
\hline EcoRI-adapters 1 and 2 & \\
EA 1.1 & CTCGTAGACTGCGTACC \\
EA 1.2 & AATTGGTACGCAGTCTAC \\
$M s e$-adapters 1 and 2 & \\
MA 1.1 & GACGATGAGTCCTGAG \\
MA 1.2 & TACTCAGGACTCAT \\
Preamplification & \\
Pre- $E c o$ RI $(+0)$ & GTAGACTGCGTACCAATTC \\
Pre- $M s e \mathrm{I}(+\mathrm{C})$ & ACGATGAGTCCTGAGTAAC \\
Selective amplification & \\
$E c o$ RI $+\mathrm{A}$ & AGACTGCGTACCAATTCA \\
$E c o$ RI+T & AGACTGCGTACCAATTCT \\
$E c o$ RI+G & AGACTGCGTACCAATTCG \\
$E c o$ RI+C & AGACTGCGTACCAATTCC \\
$M s e \mathrm{I}+\mathrm{A}$ & GATGAGTCCTGAGTAAA \\
$M s e \mathrm{I}+\mathrm{T}$ & GATGAGTCCTGAGTAAT \\
$M s e \mathrm{I}+\mathrm{G}$ & GATGAGTCCTGAGTAAG \\
$M s e \mathrm{I}+\mathrm{C}$ & GATGAGTCCTGAGTAAC \\
\hline
\end{tabular}

in the $j$ th genotype, and $\mathrm{N}_{j j}$ is the number of bands lacking in the $i$ th genotype, but present in the $j$ th genotype. By randomizing the data input order, a dendrogram was created from the similarity matrix using the unweighted pair group method with arithmetic average (UPGMA) described by Sneath and Sokal (24). PAUP 4.0* was used to generate 2,000 bootstrap replicates for testing the reliability of the dataset and to draw a consensus tree (25). Cluster analysis was performed using NTSYSpc (NTSYS - for Numerical Taxonomy SYStems) version 2.1 (22).

\section{Results}

Inoculation methods. Inoculation methods clearly differed for ability to cause infection $(P<0.0001)$ (Table 3$)$. Based on disease incidence (percentage of inoculated plants developing disease), syringe injection was significantly more efficient in identifying susceptible phenotypes $(90 \%)$ than the soil mixture (19\%). Media placement $(2 \%)$ and seed coating $(1 \%)$ rarely resulted in disease, and for the latter methods, infection rates were not significantly different from zero across the four sorghum differentials studied. No differential-isolate combination resulted in disease using other methods when it was not also positive by injection. Likewise, the overall means of four inoculation methods across $32 \mathrm{~S}$. reilianum isolates using four differentials were significantly different $(P<$ $0.0001)$. The highest disease incidence was recorded in three differentials (BTx643, SC170-6-17, and Tx7078) in the range of 83 to $98 \%$ using syringe injection, followed by 8 to $30 \%$ using soil and teliospore mixture inoculation. However, inoculation of the same differentials resulted in low infection rates $(<3 \%)$ using the other two inoculation methods (Table 3). BTx635 consistently remained disease free with any of the four inoculation methods or any of the $32 S$. reilianum isolates tested.

Pathotypes. A total of $32 \mathrm{~S}$. reilianum isolates collected from Texas were used to establish the pathotypes, using six differentials. The maize isolates collected from Mexico were not included in the pathotype study. Results for 2005, 2006, and 2009 are presented in Table 4. Of the 32 isolates studied, 23 (72\%) were identified as race 4 , including isolate 24 designated as race $4 \mathrm{~A}$. Only isolates 30 and 32 from College Station were identified as race 1. Isolates 08 and 14 from Weslaco were designated as race 6. Isolates 01, 03, 04, and 06 from Corpus Christi and isolate 16 from Weslaco were designated as race 5 .

Molecular diversity. A range of $46(E c o R I+G$ and $M s e I+T)$ to $117(E c o \mathrm{RI}+\mathrm{G}$ and $M s e \mathrm{I}+\mathrm{C})$ bands were amplified per primer combination, producing a total of 1,410 AFLP markers that were amplified from $16 \mathrm{EcoRI} / \mathrm{Mse}$ I selective primer combinations with $+1 /+1$ base extensions. Of these, 585 bands $(42 \%)$ were polymorphic among the 49 isolates genotyped (Table 5). A representative sample of the amplification products obtained using the AFLP primer combinations EcoRI-C/MseI-A is shown in Figure 2.

The genetic relationship among all AFLP patterns of $S$. reilianum based on the combination of data obtained with the 16

Table 3. Head smut disease incidence as a percentage for four inoculation methods across four sorghum differentials analyzed using a generalized linear mixed model (GLIMMIX)y

\begin{tabular}{lcccc}
\hline & \multicolumn{4}{c}{ Inoculation method } \\
\cline { 2 - 5 } & $\begin{array}{c}\text { Syringe } \\
\text { injection }\end{array}$ & Soil mix & $\begin{array}{c}\text { Media } \\
\text { placement }\end{array}$ & Seed coat \\
\hline BTx643 & $98 \mathrm{a}$ & $18 \mathrm{~b}$ & $2 \mathrm{c}^{\mathrm{z}}$ & $1 \mathrm{c}$ \\
SC170-6-17 & $90 \mathrm{a}$ & $30 \mathrm{~b}$ & $0 \mathrm{c}$ & $2 \mathrm{c}$ \\
Tx7078 & $83 \mathrm{a}$ & $8 \mathrm{~b}$ & $3 \mathrm{c}$ & $1 \mathrm{c}$ \\
Mean & $90 \mathrm{a}$ & $19 \mathrm{~b}$ & $2 \mathrm{c}$ & $1 \mathrm{c}$
\end{tabular}

${ }^{y}$ Means based on the head smut incidence of each of four replicates across four sorghum differentials; differential BTx635 is not included as it showed resistance (disease incidence $=0$ ) in all replications across all four inoculation methods.

${ }^{\mathrm{z}}$ Means within a row followed by the same letter are not significantly different at the 5\% probability level. Mean comparison was conducted using Tukey's studentized range test. 
primer combinations is represented in the dendrogram shown in Figure 3 . The similarity coefficient ranged from 0.50 to 0.94 , including two $S$. reilianum isolates from maize, and from 0.72 to 0.94 if only $S$. reilianum isolates from sorghum were included. The resultant dendrogram grouped $82 \%$ of $S$. reilianum isolates into clusters I, II, and III with $82 \%$ or higher similarity. The two maize isolates and one $S$. reilianum isolate from Uganda were distinctly separated from other sorghum head smut isolates with $50 \%$ similarity. The remaining six $S$. reilianum isolates were grouped into one small sub-cluster (IV) and four single isolate nodes (Fig 3 ). Isolates 8 and 14 from Weslaco, designated as race 6 , had the highest pair-wise similarity coefficient at $94 \%$ and were grouped in cluster I. Isolates 30 and 32 from College Station, the only two designated as race 1, were grouped in cluster II. Three isolates, 9, 17 , and 25 , designated as race 4 , were grouped in cluster IV. In clusters I, II, and III, isolates belonging to races 4 and 5 were randomly distributed.

\section{Discussion}

A major problem in development of head smut resistance programs has been the difficulty in obtaining efficient and accurate estimates of host resistance following artificial inoculation. To date, there has not been a technique superior to the syringe injec-

Table 4. Sorghum head smut race classifications based on resistant (R) or susceptible (S) responses on host differential cultivars

\begin{tabular}{lccccc}
\hline & \multicolumn{5}{c}{ Sorghum differentials } \\
\cline { 2 - 5 } Isolates & Tx7078 & $\begin{array}{c}\text { SA281 } \\
\text { (Early Hegari) }\end{array}$ & Tx414 & $\begin{array}{c}\text { SC170-6-17 } \\
\text { (TAM2571) }\end{array}$ & Race $^{\mathbf{z}}$ \\
\hline 30,32 & $\mathrm{~S}$ & $\mathrm{R}$ & $\mathrm{R}$ & $\mathrm{R}$ & 1 \\
None & $\mathrm{S}$ & $\mathrm{S}$ & $\mathrm{R}$ & $\mathrm{R}$ & 2 \\
None & $\mathrm{S}$ & $\mathrm{S}$ & $\mathrm{S}$ & $\mathrm{R}$ & 3 \\
$02,05,07,09-$ & $\mathrm{S}$ & $\mathrm{R}$ & $\mathrm{S}$ & $\mathrm{S}$ & 4 \\
13,15, 17-23, & & & & & \\
$25-29,31$ & $\mathrm{~S}$ & $\mathrm{~S}$ & $\mathrm{R}$ & $\mathrm{S}$ & $4 \mathrm{~A}$ \\
24 & $\mathrm{~S}$ & $\mathrm{R}$ & $\mathrm{R}$ & $\mathrm{S}$ & 5 \\
$01,03,04$, & $\mathrm{N}$ & $\mathrm{R}$ & $\mathrm{S}$ & $\mathrm{S}$ & 6 \\
06,16 & $\mathrm{R}$ & $\mathrm{R}$ &
\end{tabular}

y BTx635 was universally resistant and BTx643 (B1) was universally susceptible when tested against all 32 isolates.

${ }^{\mathrm{z}}$ Race classifications 1 to $4 \mathrm{~A}$ as defined by Frederiksen and Reyes (8).

Table 5. Number of bands and degree of polymorphism revealed by amplified fragment length polymorphism (AFLP) primer combinations

\begin{tabular}{lccc}
\hline $\begin{array}{l}\text { EcoRIy/MseI selective } \\
\text { amplification primer } \\
\text { combinations }\end{array}$ & $\begin{array}{c}\text { Total } \\
\text { bands }\end{array}$ & $\begin{array}{c}\text { Polymorphic } \\
\text { bands }\end{array}$ & $\begin{array}{c}\text { Polymorphism } \\
\text { rate (\%) }\end{array}$ \\
\hline E-A+M-A (E01M01) & 68 & 38 & 55.9 \\
E-A+M-C (E01M02) & 107 & 55 & 51.4 \\
E-A+M-G (E01M03) & 89 & 45 & 50.6 \\
E-A+M-T (E01M04) & 94 & 28 & 29.8 \\
E-C+M-A (E02M01) & 66 & 27 & 40.9 \\
E-C+M-C (E02M02) & 86 & 25 & 29.1 \\
E-C+M-G (E02M03) & 90 & 45 & 50.0 \\
E-C+M-T (E02M04) & 60 & 19 & 31.7 \\
E-G+M-A (E03M01) & 110 & 44 & 40.0 \\
E-G+M-C (E03M02) & 117 & 48 & 41.0 \\
E-G+M-G (E03M03) & 102 & 41 & 40.2 \\
E-G+M-T (E03M04) & 46 & 20 & 38.3 \\
E-T+M-A (E04M01) & 102 & 40 & 39.2 \\
E-T+M-C (E04M02) & 81 & 35 & 43.2 \\
E-T+M-G (E04M03) & 88 & 25 & 28.4 \\
E-T+M-T (E04M04) & 104 & 50 & 48.1 \\
Total & 1,410 & 585 & 41.5 \\
\hline ECoRI selective am
\end{tabular}

${ }^{y}$ EcoRI selective amplification primers were labeled with IRD-700 (EcoRI-A and EcoRI-G) and IRD-800 (EcoRI-C and EcoRI-T) nm fluorogenic dyes.

${ }^{\mathrm{z}}$ Standard code for AFLP primer nomenclature registered trademark of Keygene N.V. tion first described by Edmunds (5). A seedling immersion technique later developed by Craig and Frederiksen (3) may be more appropriate for evaluating field resistance, especially if intact plant surface tissues act as a barrier to infection. However, the frequency of escapes under those conditions may also lead to later problems if the pathogen is able to penetrate the meristem through wounds or natural lesions. Stringent field trials of sorghum selections identified as resistant by the seedling immersion test have not been conducted to determine if different mechanisms of host genetic resistance are involved than for resistance detected based on injection. For the maize formae speciales of Sporisorium reiliana (Sphacelotheca reiliana), artificial inoculation has proven to be relatively simple, efficient, and accurate (R. A. Frederiksen, personal observation). Quite simply, mixing smut spores with soil is very effective in maize studies, with infected maize plants being readily identified by chlorotic flecking in about 4 weeks. However, soil and teliospore mixtures were not consistent in reactions on sorghum differentials, as shown by a large range of infection efficiency and an average overall of only $19 \%$ infection of susceptible lines. It is apparent that factors other than expanded pathogenicity (i.e., some $S$. reiliana isolates cause disease in both maize and sorghum) account for differences between maize and sorghum smut populations (6).

The idea behind the seed coating and media placement techniques was that as the seed germinates, the mycelia will colonize the tissue of the apical meristem as it passes through the coated teliospore/medium. However, in all experiments using 32 isolates, low disease incidence $(<3 \%)$ indicated that neither of these inoculation methods was suitable for effective head smut resistance screening.

Syringe injection using freshly prepared inoculum was the most effective and efficient inoculation method in this study, as it produced $90 \%$ head smut incidence in susceptible sorghum differentials (Table 4). The results were consistent when the experiments were repeated over time. With syringe injection, the inoculum reaches the growing meristematic region while bypassing the surrounding tissues. Under natural infections, surrounding tissues protect the meristematic region and play a role in the resistance mechanism. One advantage of hypodermic syringe inoculation is

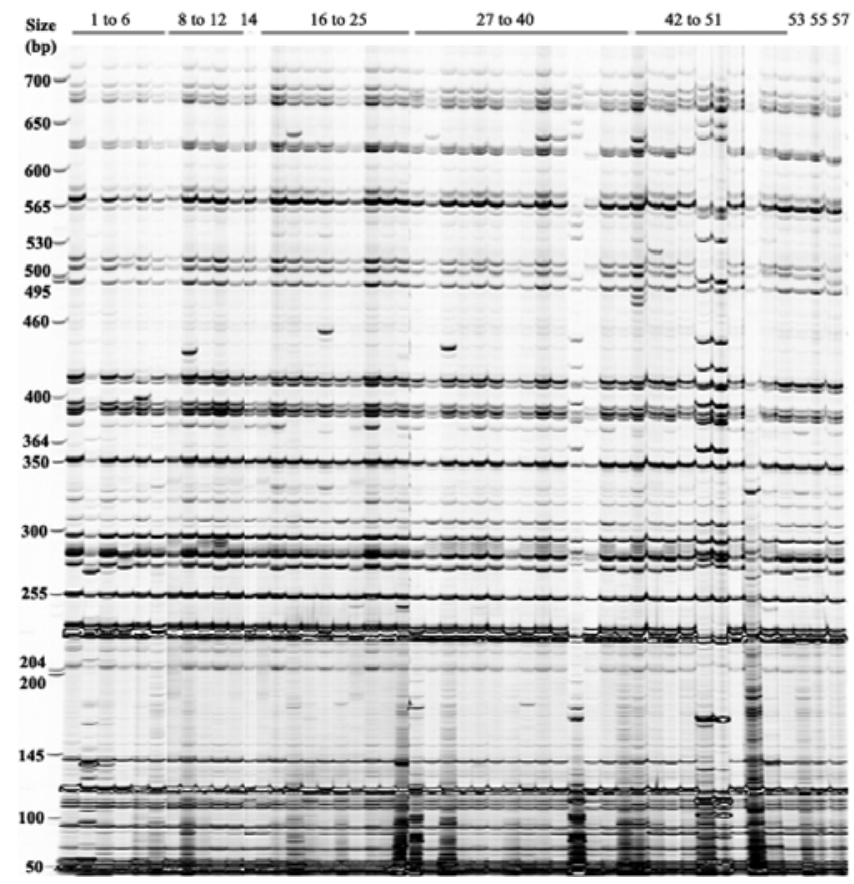

Fig. 2. Representative amplified fragment length polymorphism (AFLP) products from 49 Sporisorium reilianum isolates using EcoRI-C/Msel-A (E02M01) primers as detected using a dual labeled LI-COR system. Lanes are labeled to identify isolates. Isolates $07,13,15$, and 26 were not included in this analysis. Sizes in base pairs are indicated to the left. 


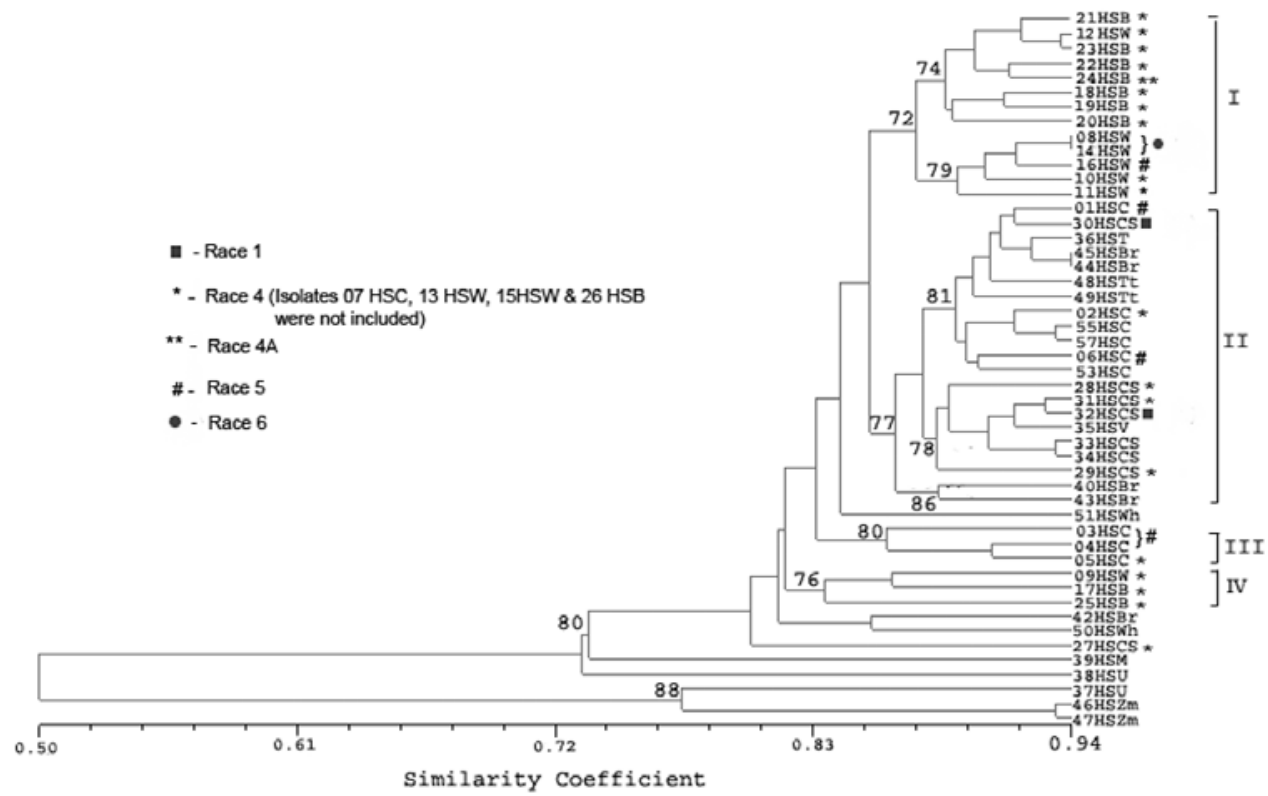

Fig. 3. Dendrogram showing four clusters (I, II, III, and IV) of 49 Sporisorium reilianum isolates using 16 amplified fragment length polymorphism (AFLP) primer combinations. Percentages from 1,000 bootstrap replications are shown near the branches of each cluster.

that it can detect type $\mathrm{R} 3$ resistance, which is expected to be more durable against new pathotypes $(3,8)$.

As a typical plant pathogenic basidiomycete, $S$. reilianum grows through the plant as dikaryotic mycelial filaments, which are formed by the union of haploid sporidia of opposing mating types. Two mating type loci (A and B) are involved, and different alleles must be present at each locus for a compatible union. At the time of flowering in the host plant, the fungus produces masses of teliospores that can survive for a decade in the soil. After karyogamy to form a diploid nucleus, teliospores germinate with the formation of a basidium, in which meiosis gives rise to the haploid spores. Thus, sexual reproduction is a regular part of the $S$. reilianum life cycle (17). As would be expected in this situation as opposed to asexual clonal reproduction, even isolates from the same geographic region were polymorphic as detected by AFLP analysis, but the closest matches generally also came from nearby isolates. For example, both race 6 isolates were collected near Weslaco and have similar but nonidentical AFLP patterns. Likewise, two maize isolates of $S$. reilianum available from a previous study (18) were genetically similar but distinctly different from all the Texas isolates, as were isolates from Africa that were available from the same study. However, the presence of sorghum isolates of both races 4 and 5 in all of the clusters (Fig. 2), and the rarity of races 1 and 2 that were formerly common, suggest that hosts compatible with these races have selected for a shift in the $S$. reilianum population over the 20 to 30 years since the previous study. Whether the widespread presence of race 4 means susceptible sorghum cultivars are now being grown, or perhaps that race 4 can reproduce on a weedy relative such as Johnsongrass, it seems likely that the new races could have arisen from the extant population and are likely to become even more prevalent since they are being found on sorghum varieties previously considered to be head smut resistant. S. reilianum incidence has also been observed in previously resistant hybrids in the last 3 years in the sorghum-growing areas of northeast Mexico, where many of the same hybrids are grown. Races 5 and 6 had not been previously identified, and hence resistance to these two new races should be incorporated into grain sorghum cultivars now being bred for commercial use. Since it is resistant to all the isolates tested, BTx635 is a potential source of added resistance.

Electrophoretic karyotype analysis has shown $S$. reilianum to have a genome size of approximately $15 \mathrm{Mb}$ (18). Little research has been done to examine the optimization of base extension in selective amplification in taxa with small genomes to increase the number of bands obtained and, hence, the complexity of the AFLPs
(11). Furthermore, a lower limit exists to the number of fragments needed to produce a reliable and artifact-free profile. Kuiper et al. (14) recommend that primers generating fewer than 10 bands be avoided. Here, the use of selective primers with zero to one selective base extensions was found to optimize the number of informative bands generated by means of AFLP analysis. This modified method for detecting AFLPs is especially appropriate because it requires minimal amounts of genomic DNA for use with a large number of primer combinations.

One of the advantages of using AFLPs for screening is that many sites throughout the genome are sampled simultaneously. Markers developed from AFLP detect an abundance of polymorphisms in a wide range of taxa, including plants, fungi, and bacteria. Also, this technique has been used to uncover cryptic genetic variation of strains or closely related species, even at the isolate level, that have been impossible to resolve with morphological or other molecular systematic characters $(1,2)$. Although the sample numbers of each pathotype in our study were too low to detect any associated AFLP pattern, it should become possible to identify DNA-based markers that will permit rapid pathotype determination for a pathogen that cannot otherwise be scored until the host reaches maturity.

\section{Literature Cited}

1. Bakkeren, G., Kronstad, J. W., and Levesque, C. A. 2000. Comparison of AFLP fingerprints and ITS sequences as phylogenetic markers in Ustilaginomycetes. Mycologia 92:510-521.

2. Blears, M. J., De Grandis, S. A., Lee, H., and Trevors, J. T. 1998. Amplified fragment length polymorphism (AFLP): A review of the procedure and its applications. J. Ind. Microbiol. Biotechnol. 21:99-114.

3. Craig, J., and Frederiksen, R. A. 1992. Comparison of sorghum seedling reactions to Sporisorium reilianum in relation to sorghum head smut resistant classes. Plant Dis. 76:314-318.

4. Dodman, R. L., Obst, N. R., and Henzell, R. G. 1985. Races of sorghum head smut (Sporisorium reilianum) in south-east Queensland. Australas. Plant Pathol. 14: 45

5. Edmunds, L. K. 1963. Use of sporidial hypodermic injection to test sorghum for head smut resistance. Plant Dis. Rep. 47:909-913.

6. Frederiksen, R. A. 1977. Head smuts of corn and sorghum. Pages 98-105 in: Proc. 32nd Annu. Corn Sorghum Research Conf., Lubbock, TX.

7. Frederiksen, R. A. 2000. Disease and disease management in sorghum. Pages 497-533 in: Sorghum - Origin, History, Technology and Production. C. Smith and R. A. Frederiksen, eds. John Wiley \& Sons, New York.

8. Frederiksen, R. A., and Reyes, L. 1980. The head smut program at Texas A\&M. Pages 367-372 in: Sorghum Diseases: A World Review. ICRISAT, Patancheru, India.

9. Huys, G., Coopman, R., Janssen, P., and Kersters, K. 1996. High resolution genotypic analysis of the genus Aeromonas by AFLP fingerprinting. Int. J. 
Syst. Bacteriol. 48:572-580.

10. Jaccard, P. 1908. Nouvelles recherches sur la distribution florale. Bull. Soc. Vaud. Sci. Nat. 44:223-270.

11. James, C. M., Lesemann, S. S., and Down, G. J. 2003. Modified AFLP analysis method for species with small genomes. Plant Mol. Biol. Rep. 23:303-307.

12. Klein, P. E., Klein, R. R., Cartinhour, S. W., Ulanch, P. E., Dong, J., Obert, J. A., Morishige, D. T., Schlueter, S. D., Childs, K. L., Ale, M., and Mullet, J. E. 2000. A high-throughput AFLP-based method for constructing integrated genetic and physical maps: Progress toward a sorghum genome map. Genome Res. 10:789-807.

13. Kresovich, S., Barbazuk, B., Bedell, J. A., Borrell, A, Buell, C. R., Burke, J., Clifton, S., Cordonnier-Pratt, M. M., Cox, S., Dahlberg, J., Erpelding, J., Fulton, T. M., Fulton, B., Fulton, L., Gingle, A. R., Hash, C. T., Huang, Y., Jordan, D., Klein, P. E., Klein, R. R., Magalhaes, J., McCombie, R., Moore, P., Mullet, J. E., Ozias-Akins, P., Paterson, A. H., Porter, K., Pratt, L., Roe, B., Rooney, W., Schnable, P. S., Stelly, D. M., Tuinstra, M., Ware, D., and Warek, U. 2005. Toward Sequencing the Sorghum Genome. A U.S. National Science Foundation-Sponsored Workshop Report. Plant Physiol. 138:1898-1902.

14. Kuiper, M. T. R. 1996. Building a high density genetic map using the AFLP ${ }^{\mathrm{TM}}$ technology. In: Methods in Molecular Biology - Arabidopsis Protocols. J. Martinez-Zapater and J. Salinas, eds. Humana Press, Totowa, NJ.

15. Majer, D., Lewis, B. G., and Mithen, R. 1998. Genetic variation among field isolates of Pyrenopeziza brassicae. Plant Pathol. 47:22-28.

16. Marley, P. 1995. Cynodon dactylon: An alternative host for Sporisorium sorghi, causal organism of sorghum covered smut. Crop Prot. 14:491-493.

17. Martinez, C., Roux, C., and Dargent, R. 1999. Biotrophic development of Sporisorium reilianum $\mathrm{f}$. sp. zeae in vegetative shoot apex of maize. Phytopathology 89:247-253.

18. Naidoo, G., and Torres-Montalvo, H. 2002. Genetic variability among and within host specialized isolates of Sporisorium reilianum. Pages 221-225 in: Sorghum and Millets Diseases. J. F. Leslie, ed. Iowa State Press, A Blackwell Publishing Company, Ames, IA.

19. Okori, P., Rubaihayo, P. R., Ekwamu, A., Fahleson, J and Dixelius, C. 2004. Genetic characterization of Cercospora sorghi from cultivated and wild sorghum and its relationship to other Cercospora fungi. Phytopathology 94:743-750.

20. Osorio, J. A., and Frederiksen, R. A. 1998. Development of an infection assay for Sporisorium reilianum, the head smut pathogen on sorghum. Plant Dis. 82:1232-1236.

21. Ramasamy, P., Frederiksen, R. A., Prom, L. K., and Magill, C. W. 2007. Head Smut. Pages 58-63 in: Screening Techniques for Sorghum Diseases. R. Thakur, B. Reddy, and K., Mathur, eds. International Crops Research Institute for the Semi-Arid Tropics (ICRISAT), Patancheru, India.

22. Rohlf, F. J. 2000. NTSYS-pc Numerical Taxonomy and Multivariate Analysis System, Ver. 2.1. Exeter Publications, New York.

23. Samuels, G. J., and Siefert, K. A. 1995. The impact of molecular characters on systematics of filamentous ascomycetes. Annu. Rev. Phytopathol. 33:3767.

24. Sneath, P. H. A., and Sokal, R. R. 1973. Numerical Taxonomy. The Principles and Practices of Classification. W. H. Freeman and Co., San Francisco, CA.

25. Swofford, D. L. 2002. PAUP*: Phylogenetic Analysis Using Parsimony (*and other methods). Sinauer Associates, Sunderland, MA.

26. Vos, P., Hogers, R., Bleeker, M., Reijans, M., van de Lee, T., and Others. 1995. AFLP: A new technique for DNA fingerprinting. Nucleic Acids Res. 23:4407-4414.

27. Zhou, Y. L., Pan, Y. J., Xie, X. W., Zhu, L. H., Xu, J. L., Wang, S., and Li, Z. K. 2008. Genetic diversity of rice false smut fungus, Ustilaginoidea virens and its pronounced differentiation of populations in North China. J. Phytopathol. 156:559-564. 